\title{
New Keynesian Optimal-Policy Models: An Empirical Assessment*
}

\author{
Richard Dennis ${ }^{\dagger}$ \\ Federal Reserve Bank of San Francisco
}

This version December, 2003

First version August, 2003

\begin{abstract}
This paper estimates two optimization-based sticky-price New Keynesian models and assesses how well they describe US output, inflation, and interest rate dynamics. We consider models in which either internal habit formation or external habit formation influence consumption behavior, and in which Calvopricing and inflation indexation generate price and inflation inertia. Subject to constraints dictated by household and firm behavior, monetary policy is set under discretion and the model's time-consistent equilibrium is employed to estimate key behavioral parameters. We find that specifications estimated on consumption data perform better than specifications estimated on output data and that models with external habit formation out-perform models with internal habit formation. Nevertheless, even the best fitting specification displays characteristics that are inconsistent with the data.

Keywords: Habit Formation, Inflation Dynamics, Optimal Policy.
\end{abstract}

JEL Classification: E52, E58.

${ }^{*}$ I would like to thank Graeme Wells and Carl Walsh for comments. The views expressed in this paper do not necessarily reflect those of the Federal Reserve Bank of San Francisco or the Federal Reserve System.

$\dagger$ Address for Correspondence: Economic Research, Mail Stop 1130, Federal Reserve Bank of San Francisco, 101 Market St, CA 94105, USA. Email: richard.dennis@sf.frb.org. 


\section{Introduction}

The canonical sticky-price New Keynesian model (Goodfriend and King, 1997; Rotemberg and Woodford, 1997) forms the backbone to a large body of research into optimal monetary policy (Clarida, Galí, and Gertler, 1999; Jensen, 2002; Walsh, 2003). The model consists of just two equations, a forward-looking IS curve, capturing consumption smoothing behavior, and a forward-looking Phillips curve, derived from optimal price setting in the presence of nominal rigidities. An attractive feature of the canonical model is that it is analytically tractable in many applications. However, as an empirical description of macroeconomic dynamics, the model performs poorly. Estrella and Fuhrer (2002) and Rudd and Whelan (2003) show that the canonical New Keynesian Phillips curve leads to counterfactual price movements and that it has very little explanatory power. Similarly, Fuhrer and Rudebusch (2002) find that the canonical New Keynesian IS curve - a critical component in the monetary policy transmission mechanism - provides a very poor description of output dynamics and that it is convincingly rejected by US data. ${ }^{1}$ Moreover, it still remains to be established whether estimated Taylor-type rules (Taylor, 1993), which are closely connected to the New Keynesian framework, are the outcome of optimal policy behavior (Dennis, 2001; Rudebusch, 2001).

When it comes to explaining observed economic outcomes, a critical shortcoming with the canonical model is that it provides no mechanism for generating persistence. ${ }^{2}$ No capital accumulation takes place and both inflation and consumption/output are jump variables. Because it contains no endogenous dynamics, without introducing serially correlated shocks, the model cannot account for the persistence that is present in inflation and output data. To counter these empirical weaknesses, much research now focuses on models that generalize the canonical model to contain features such as habit formation (McCallum and Nelson, 1999), wage and price stickiness (Erceg, Henderson, and Levin, 2000), and price indexation (Christiano, Eichenbaum, and Evans, 2001), features that are explicitly designed to generate persistence. However, many studies that use generalized, or hybrid, New Keynesian models do not estimate

\footnotetext{
${ }^{1}$ In fact, depending on how monetary policy is modeled, the canonical new Keynesian IS/Phillips curves may not even be estimable, i.e., the structural parameters in these equations may not be identified (Dennis, 2003; Nason and Smith, 2003).

${ }^{2}$ See the model specification laid out in Clarida, et al. (1999, section 2$)$ for example.
} 
the model, but simply assign values to parameters (Erceg, et al., 2000; Amato and Laubach, 2003). Thus, while hybrid models should have greater empirical content than the canonical model, it is not clear that they explain observed macroeconomic outcomes, leaving question marks hanging over the conclusions and policy prescriptions drawn from them.

In this paper we formulate and estimate several optimization-based New Keynesian models with Calvo-pricing, price indexation, and habit formation, providing estimates of the parameters that govern these important New Keynesian features. We consider both internal habit formation, where households internalize the effect their past consumption has on the marginal utility of current consumption, and external habit formation, where a household's marginal utility of consumption is lowered when others consume more. These models are standard generalizations on the canonical New Keynesian model, and exhibit the lead/lag structures in output and inflation that are typical of the specifications analyzed in the optimal monetary policy rules literature (see Clarida, et al., 1999, section 6). The models are estimated on US data, using multiple measures of the output/consumption gap, inflation, and short-term interest rates, and assessed against Vector AutoRegressions (VARs).

Rather than estimate the models using single-equation estimation methods - ignoring the cross-equation restrictions implied by the underlying theory - we estimate the models as a system using Full Information Maximum Likelihood (FIML). Estimating the models as a system not only facilitates an efficiency gain, but it also allows us to estimate parameters that cannot be identified with single-equation methods. To apply FIML some assumption must be made about how monetary policy is formulated. While we could simply postulate and estimate an interest rate rule, we choose instead to remain within an optimization-based framework and to assume that the monetary authority is an optimizing agent that sets policy according to an optimal discretionary rule. Consequently, we postulate an objective function for the monetary authority, ${ }^{3}$ solve for the time-consistent policy rule, and estimate the parameters in the policy objective function alongside the structural parameters in the optimization constraints.

\footnotetext{
${ }^{3}$ We use the standard quadratic that is widely used in the monetary policy rules literature (Bryant, Hooper, and Mann, 1993; Taylor, 1999).
} 
The models that we consider have aspects in common with those derived in Christiano, et al. (2001) and in Smets and Wouters (2002). Unlike those studies, however, we explicitly model the monetary policy formulation process, allowing monetary policy to be set optimally rather than according to a simple instrument rule. An important payoff to modeling the central bank as an optimizing agent is that it allows us to estimate the parameters in the policy objective function and to compare these estimates to the values typically used in the optimal monetary policy rules literature. Moreover, because we do not estimate the models on de-meaned data, we are able to estimate the equilibrium real interest rate, the implicit inflation target, and to test whether monetary policy created a discretionary inflation bias.

Several important results emerge from our analysis. First, while introducing (internal or external) habit formation and price indexation leads to a statistically significant improvement in the models' ability to fit US data, the resulting specifications are, nevertheless, still inconsistent with the data. Second, according to standard information criteria, models with external habit formation describe US data better than models with internal habit formation. Moreover, with external habit formation the estimates of the intertemporal elasticity of substitution that are obtained are more in line with estimates found in other studies. However, the process by which habits are formed differs importantly depending on whether the model is estimated on output data or on consumption data. These differences suggest that what is perceived as habit formation may partially reflect other dynamic mechanisms, such as capital accumulation, in specifications estimated on output data.

Third, for the Volcker-Greenspan period, we obtain plausible estimates of the implicit inflation target and find evidence for interest rate smoothing. However, evidence for output stabilization is weak and we find no evidence for a discretionary inflation bias. Fourth, for both the internal habit formation model and the external habit formation model, the estimates suggest that around 20 percent of firms reoptimize their price each quarter. Finally, we find that the New Keynesian optimalpolicy models perform better when estimated on consumption data than on output data. This last result is notable because New Keynesian models are typically applied or calibrated to output gap specifications.

The remainder of this paper is structured as follows. In the following Section the 
models that are estimated are presented. Section 3 describes the data on which the models are estimated and shows how each model's time-consistent equilibrium can be used to estimate its behavioral parameters. In Section 4 the models are estimated and the results are interpreted and compared to other estimates in the literature. Section 5 assesses the models to determine which specification best conforms to the data. The selected specifications are then compared to a VAR model to help identify areas where the New Keynesian models are inconsistent with the data. Section 6 concludes.

\section{The Models}

The models that we consider contain the central features of the New Keynesian optimal-policy apparatus. We do not present the models' derviations in complete detail because numerous closely related expositions are available in the literature (Smets and Wouters, 2002; Amato and Laubach, 2003).

\section{$2.1 \quad$ Firms}

Firms are monopolistically competitive. They maximize the expected discounted value of future profits, pricing along their demand curve to set prices as a fixed markup over marginal costs. Following Calvo (1983), each period a fixed proportion of firms, $1-\xi_{p}\left(0 \leq \xi_{p} \leq 1\right)$, receive a signal to re-optimize their price while firms that do not re-optimize index their price change to last period's inflation rate (Christiano, et al., 2001). The first-order condition for optimal price-setting combined with price indexation by non-optimizing firms, when log-linearized about the economy's nonstochastic steady state, leads to aggregate inflation, $\pi_{t}$, evolving according to

$$
\pi_{t}=\frac{1}{1+\beta} \pi_{t-1}+\frac{\beta}{1+\beta} E_{t} \pi_{t+1}+\frac{\left(1-\beta \xi_{p}\right)\left(1-\xi_{p}\right)}{(1+\beta) \xi_{p}} \widehat{m c}_{t} .
$$

In equation (1), $\widehat{m c}_{t}$ represents real marginal costs, which, because there is no capital in production, simply equals the real wage divided by the marginal product of labor. Any profits that firms earn are returned to households (the shareholders) in the form of a lump-sum dividend payment. 


\subsection{Households}

Households are infinitely lived and have identical preferences over consumption relative to habit consumption, real money balances, and leisure. They consume a Dixit-Stiglitz aggregate of the goods that firms produce and they rent their labor to firms in a perfectly competitive labor market. Households can transfer wealth through time either by holding one-period bonds, which earn the nominal rate $R_{t}$, or by holding real money balances. The representative household's expected lifetime utility is given by

$$
U=E_{t} \sum_{i=0}^{\infty} \beta^{i} u\left(C_{t+i}, H_{t+i}, L_{t+i}, \frac{M_{t+i}}{P_{t+i}}\right),
$$

where $C_{t}$ denotes final goods consumption, $H_{t}$ denotes habit consumption, $L_{t}$ denotes

labor supply, $\frac{M_{t}}{P_{t}}$ denotes real money balances, and $\beta(0<\beta<1)$ is the subjective discount factor. The subjective discount factor that enters equation (1) is the same as that entering the households' utility function because future profits are valued in terms of the extra utility they provide to households.

Under the assumption that households have internal habit formation, $H_{t}=C_{t-1}^{\gamma}$ and the instantaneous utility function is taken to be

$$
u(., ., ., .)=\frac{e^{g_{t}}\left(\frac{C_{t}}{C_{t-1}^{\gamma}}\right)^{1-\sigma}}{1-\sigma}+\frac{\left(\frac{M_{t}}{P_{t}}\right)^{1-\alpha}}{1-\alpha}-\frac{L_{t}^{1+\theta}}{1+\theta} .
$$

According to equation (3), the marginal utility of consumption for a household is declining in the quantity of goods consumed by that household last period. With this specification for utility, the household seeks to smooth both the level and the growth rate of consumption through time and the desire to keep changes in consumption small leads to inertia, or persistence, in consumption. The parameters, $\sigma, \alpha$, and $\theta(\sigma, \alpha, \theta>0)$ regulate the curvature of the utility function with respect to consumption, real money balances, and leisure, respectively, while $\gamma(|\gamma|<1)$ indexes the degree of habit formation. When $\gamma$ is positive habit formation is present; when $\gamma$ is negative consumption can be viewed as a durable good. Also entering the instantaneous utility function is a consumption preference shock, $g_{t}$, which is assumed to be an iid, zero mean, finite variance, random variable. 
To model external habit formation, we assume that the household conditions on $H_{t}$ when making its consumption decision, that $H_{t}$ evolves according to

$$
H_{t}=\gamma_{1} C_{t-1}+\gamma_{2} C_{t-2}
$$

where $\left|\gamma_{1}+\gamma_{2}\right|<1$, and that the instantaneous utility function is given by

$$
u(., ., ., .)=\frac{e^{g_{t}}\left(C_{t}-H_{t}\right)^{1-\sigma}}{1-\sigma}+\frac{\left(\frac{M_{t}}{P_{t}}\right)^{1-\alpha}}{1-\alpha}-\frac{L_{t}^{1+\theta}}{1+\theta} .
$$

Under external habit formation, a household's marginal utility of consumption is declining in the level of past aggregate consumption, producing behavior in which households try to "keep up with the Joneses."

Regardless of whether the household has internal or external habit formation, the budget constraint facing the representative household is

$$
C_{t}+\frac{M_{t+1}}{P_{t}}+\frac{B_{t+1}}{P_{t}}=\frac{W_{t}}{P_{t}} L_{t}+\frac{\left(1+R_{t}\right)}{P_{t}} B_{t}+\frac{M_{t}}{P_{t}}+\frac{\Pi_{t}}{P_{t}}
$$

where $B_{t}$ represents nominal bond holdings brought into period $t$ and $\Pi_{t}$ is the lumpsum dividend payment that households receive from firms.

The log-linearized first-order conditions from the households optimization problem can be written as

$E_{t} \Delta \widehat{c}_{t+1}=\frac{\gamma(\sigma-1)}{[\sigma+\gamma \beta(\sigma \gamma-1-\gamma)]}\left[\Delta \widehat{c}_{t}+\beta E_{t} \Delta \widehat{c}_{t+2}+\frac{1}{\gamma(\sigma-1)} E_{t}\left(R_{t}-\pi_{t+1}+\ln (\beta)-g_{t}\right)\right]$

for the internal habit formation model, and as

$\widehat{c}_{t}=\frac{\left(\gamma_{1}-\gamma_{2}\right)}{\left(1+\gamma_{1}\right)} \widehat{c}_{t-1}+\frac{\gamma_{2}}{\left(1+\gamma_{1}\right)} \widehat{c}_{t-2}+\frac{1}{\left(1+\gamma_{1}\right)} E_{t} \widehat{c}_{t+1}-\frac{\left(1-\gamma_{1}-\gamma_{2}\right)}{\sigma\left(1+\gamma_{1}\right)} E_{t}\left(R_{t}-\pi_{t+1}+\ln (\beta)-g_{t}\right)$

for the external habit formation model. While the lead-lag structures for consumption are considerably more complicated than those from the standard time-separable utility formulation, the coefficients on the consumption terms in equations (7) and (8) sum to one. Thus, even with habit formation, an increase in permanent income leads to a permanent increase in consumption.

To close the model we assume that real marginal costs are related to the "consumption gap" according to $\widehat{c}_{t}=\widehat{m c}_{t}+u_{t}$. While clearly an approximation, this 
assumption yields a Phillips curve in inflation/gap space and is an assumption that is explicitly or implicitly made in most of the New Keynesian literature. The advantage of this simple relationship between the gap and real marginal costs is that it simplifies the estimation, allows the model estimates to be compared to those in other studies, and bypasses the need to specify an explicit production technology. At the same time, estimates that are based on a microfounded relationship between the "consumption gap" and real marginal costs are of considerable interest; work underway addresses this issue (Dennis, 2003).

The internal-habit-formation model and the external-habit-formation model derived above represent two popular generalizations on the canonical New Keynesian model. A large literature has developed that examines optimal monetary policy in models closely related to these. A critical characteristic of these models is that they abstract from investment and capital accumulation as well as from open economy considerations. ${ }^{4}$ In some ways this abstraction is a convenience to simplify the models' derivations. However, abstracting from capital accumulation also reflects the focus of the New Keynesian optimal policy literature, which concentrates on shorterrun macroeconomic stabilization issues and not on longer-run growth issues for which supply-side considerations are thought to be more important (McCallum and Nelson, 1997). But, because the economy is closed and because there is no investment, the economy's resource constraint implies that for these models output dynamics and consumption dynamics should be the same.

\subsection{Central Bank}

The central bank is the only other decision-making agent in the model. The central bank is assumed to set the short-term nominal interest rate, $R_{t}$, subject to constraints dictated by the behavior of households and firms, in order to minimize the loss function

$$
\operatorname{Loss}(t, \infty)=E_{t} \sum_{j=0}^{\infty} \beta^{j}\left[\left(\pi_{t+j}-\pi^{*}\right)^{2}+\lambda\left(\widehat{c}_{t+j}-c^{*}\right)^{2}+\nu\left(\Delta R_{t+j}\right)^{2}\right] .
$$

This policy objective function allows for an inflation stabilization objective, an consumption gap stabilization objective, and an interest rate smoothing objective.

\footnotetext{
${ }^{4}$ See Galí and Monacelli (2000) for an extension of the canonical New Keynesian model to the open economy.
} 
In the inflation stabilization term, $\pi^{*}$ represents the central bank's implicit inflation target. We assume that the central bank cannot precommit and that it sets monetary policy under discretion. Consequently, we allow the parameter $c^{*}$ to enter the consumption stabilization objective to examine whether policymakers face an incentive to create a discretionary inflation bias. ${ }^{5}$ The two policy preference parameters, $\lambda$ and $\nu$, the relative weights on consumption stabilization and on interest rate smoothing, are required to be non-negative.

Equation (9) has not been derived from a second-order approximation to the household's utility function, although the analysis in Woodford (2002) suggests that such an approximation would yield a similar specification. If a second order approximation to household utility were used, then the parameters $\lambda, \nu$, and $c^{*}$ would be functions of the model's utility and technology parameters. When it comes to estimating the model, we assume that monetary policy is set with discretion and allow for the possibility that a Rogoff (1985) optimally conservative central banker - who has preferences that differ from the representative household - has been appointed. For this reason we allow $\lambda, \nu$, and $c^{*}$ to be freely estimated, subject to non-negativity constraints on $\lambda$ and $\nu$.

\section{Data and Model Estimation}

\subsection{Data}

The models that we estimate consist of a forward-looking IS curve, either equation (7) or equation (8), a hybrid Phillips curve, equation (1), and a loss function, equation (9). To estimate the models we require data for $\widehat{c}_{t}, \pi_{t}$, and $R_{t}$. The economy's resource constraint posits that consumption and output are equal, so, in principle, the model can be estimated on either consumption or output data. In what follows, we use data on both variables and use several techniques to de-trend each series. The data are summarized in Table 1.

\footnotetext{
${ }^{5}$ Of course, even if there is no discretionary inflation bias in the time-consistent equilibrium, the model's dynamic behavior will still be inefficient due to a stabilization bias (Dennis and Söderström, 2002).
} 


\begin{tabular}{c|c}
\hline \hline & Table 1: Data Definitions \\
\hline \hline$\widehat{y}_{t}^{1}$ & $($ log- $)$ ratio of GDP to CBO measure of potential \\
$\widehat{y}_{t}^{2}$ & $(\log -)$ GDP de-trended using HP filter \\
$\widehat{y}_{t}^{3}$ & $(\log -)$ GDP /Labor Force de-trended using HP filter \\
$\widehat{c}_{t}^{1}$ & $($ log- $)$ Consumption de-trended using HP filter \\
$\widehat{c}_{t}^{2}$ & $(\log -)$ Consumption/Labor Force de-trended using HP filter \\
\hline$\pi_{t}^{y}$ & Annualized quarterly percent change in GDP price index \\
$\pi_{t}^{c}$ & Annualized quarterly percent change in core-PCE price index \\
\hline$R_{t}^{f}$ & Nominal federal funds rate \\
$R_{t}^{T}$ & Nominal 3-month T-Bill rate \\
\hline \hline
\end{tabular}

We use five gap measures: three output gaps and two consumption gaps. The first output gap, $\widehat{y}_{t}^{1}$, in which real GDP is de-trended using the Congressional Budget Office (CBO) measure of potential output, is the same as that Rudebusch and Svensson (1999) use to study optimal simple policy rules. Using this measure of the output gap provides a bridge between our results and the results that emerge from studies that employ the Rudebusch-Svensson framework. We also construct an output gap, $\widehat{y}_{t}^{2}$, and a consumption gap, $\widehat{c}_{t}^{1}$, by de-trending using the Hodrick-Prescott filter. However, to be consistent with the representative-agent characterization of the households' optimization problem, the remaining two gap measures, $\widehat{y}_{t}^{3}$ and $\widehat{c}_{t}^{2}$, are constructed from per-labor-force measures of output and consumption. We detrend (log-) output-per-labor-force and (log-) consumption-per-labor-force using the Hodrick-Prescott filter.

The three output gap measures and the two consumption gap measures are displayed in Figure 1A and Figure 1B, respectively, for the period 1956.Q1 - 2002.Q2. Looking at Figure 1A, by-and-large, the three output gap variables move in sympathy; the recessions in the early 1980s and in the early 1990s are clearly evident. However, when the output gap is constructed using the CBO measure of potential output, $\widehat{y}_{t}^{1}$, the resulting output gap is noticeably more volatile than the other two measures. Moreover, while the correlation between $\widehat{y}_{t}^{2}$ and $\widehat{y}_{t}^{3}$ is 0.97 , the correlation between $\widehat{y}_{t}^{1}$ and either $\widehat{y}_{t}^{2}$ or $\widehat{y}_{t}^{3}$ is only about 0.77 . Turning to Figure $1 \mathrm{~B}$, in terms of the timing and amplitude of the business cycle, the two consumption gap variables tell a similar story to the three output gap variables. Although $\widehat{c}_{t}^{2}$ is slightly more volatile than $\widehat{c}_{t}^{1}$, their correlation is 0.95 . These output gap and consumption gap variables illustrate the relative stability the US economy has experienced following 


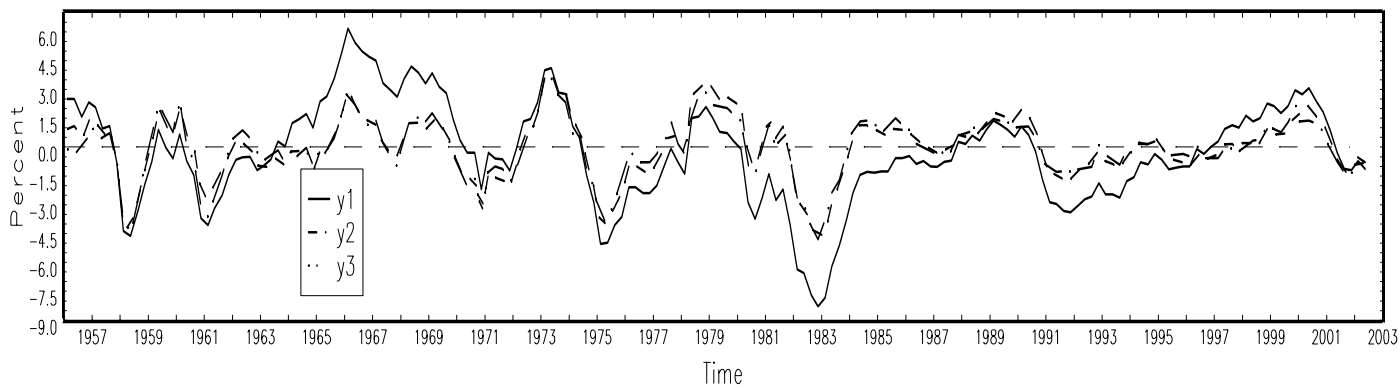

Panel B: Consumption Gaos

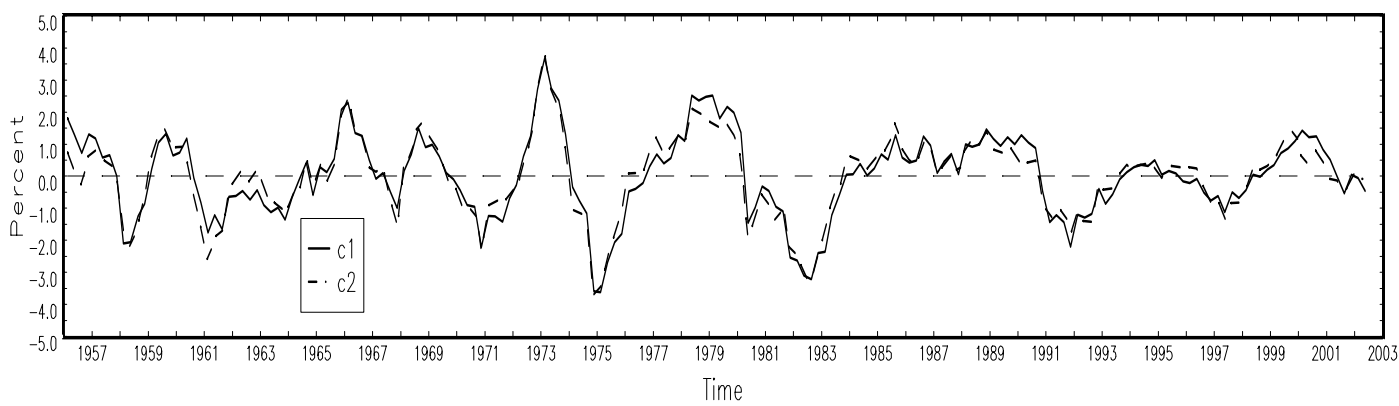

Panel C: Inflation Rates

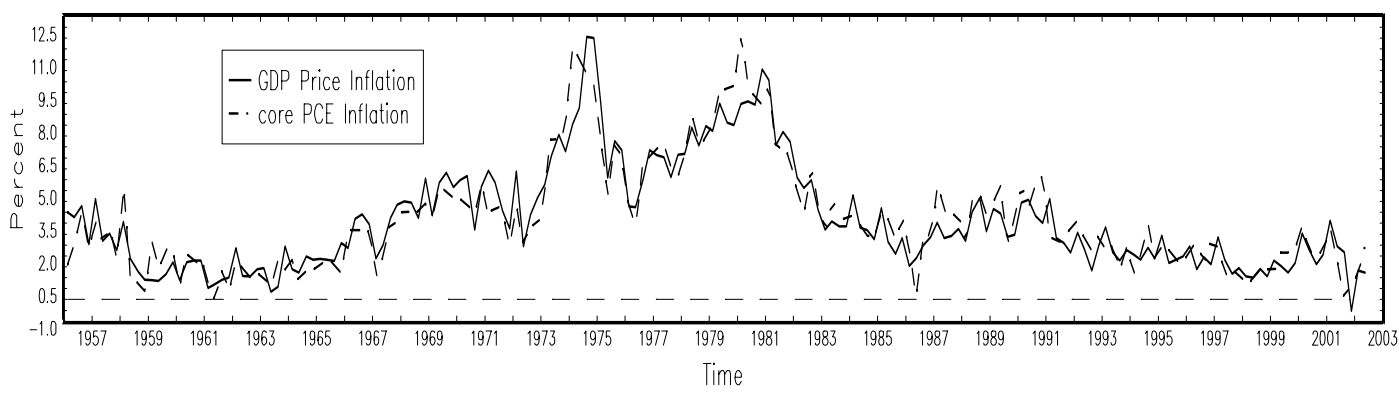

Panel D: Nominal Interest Rate

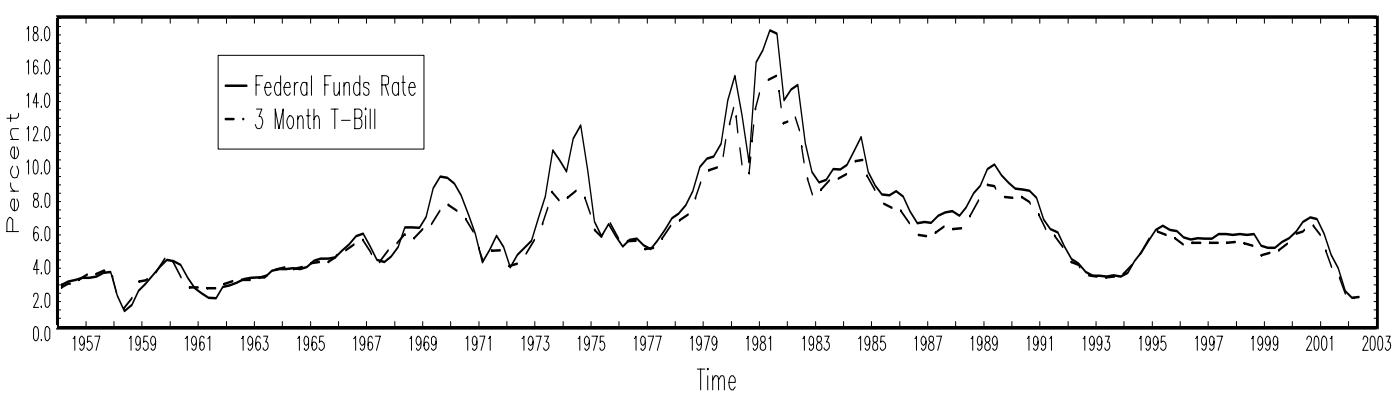

Figure 1: Post WWII Data 
1984 (or so) relative to the 1960s and 1970s. As discussed earlier, this decline in volatility may be due to a decline in the variance of demand shocks.

Two measures of inflation, $\pi_{t}$, are used. When the model is estimated on one of the three output gap variables inflation is measured as the annualized quarterly percent change in the GDP price index, and is denoted $\pi_{t}^{y}$. In contrast, when one of the two consumption gap variables is used for estimation, inflation is measured as the annualized quarterly percent change in the core-PCE price index, and is denoted $\pi_{t}^{c}$. The two inflation variables are shown in Figure 1C. The most prominent feature of Figure 1C is the rapid rise in inflation that occurred in the 1970s following the oil price shocks, and the subsequent drop in inflation that occurred in the 1980s, associated with the Volcker-recession. The standard deviation of GDP price inflation is 2.43 percent while that for core-PCE price inflation is 2.52 percent; the correlation between the two inflation variables is 0.93 .

The inflation data and the consumption gap and output gap data are both measured at the quarterly frequency. Because quarterly data are used, it is natural to take one quarter to be the length of a period in the theoretical model. For this reason, the one-period bond that enters the model can be thought of as an asset such as a 3-month T-bill. However, when modeling the central bank's optimization problem we assume that the interest rate on the one-period bond is the central bank's policy instrument, which makes it natural to associate $R_{t}$ with the federal funds rate. When estimating the models, then, we will use both the quarterly average federal funds rate and the quarterly average yield on 3-month T-bills to represent $R_{t}$. As can be seen in Figure 1D, the main difference between these two interest rate series is their level. The 3-month T-bill rate typically lies below the federal funds rate, particularly at times when inflation is high. It is notable that short-term nominal interest rates rose rapidly when inflation climbed in the late-1970s, but rose less rapidly when inflation began to pickup in 1973. This relationship between inflation and short term nominal interest rates has led to the view that monetary policy accommodated rising inflation in the early- to mid-1970, when Arthur Burns was FOMC chairman, but "lent-against-the-wind" in the late-1970s, when Paul Volcker became FOMC chairman. The standard derivations of the federal funds rate and of the 3-month T-bill rate are 3.25 percent and 2.67 percent, respectively; their correlation is 0.99 . 


\subsection{Model Estimation}

To estimate the model it must first be transformed into a suitable form. Specifically, we need to solve for the time-consistent solution to the optimal policy problem and manipulate the resulting equilibrium relationships to remove variables that are endogenous, but not stochastic endogenous. The goal is to arrive at a specification that contains only stochastic endogenous variables (so that the system has a full set of shocks), thereby avoiding a stochastic singularity.

Let $\mathbf{z}_{t}=\left[\begin{array}{c}\mathbf{z}_{t}^{s} \\ \mathbf{z}_{t}^{i}\end{array}\right]$, where $\mathbf{z}_{t}^{s}\left(n_{s} \times 1\right)$ contains stochastic endogenous variables and $\mathbf{z}_{t}^{i}\left(n_{i} \times 1\right)$ contains endogenous variables defined by identities. The optimization constraints can be written as

$$
\mathbf{A}_{0} \mathbf{z}_{t}=\mathbf{a}+\mathbf{A}_{1} \mathbf{z}_{t-1}+\mathbf{A}_{2} E_{t} \mathbf{z}_{t+1}+\mathbf{A}_{3} \mathbf{x}_{t}+\mathbf{u}_{t}
$$

The solution to the central bank's optimization problem yields a time-consistent equilibrium of the form (see Dennis, 2003)

$$
\left[\begin{array}{c}
\mathbf{z}_{t}^{s} \\
\mathbf{z}_{t}^{i}
\end{array}\right]=\left[\begin{array}{c}
\mathbf{h}^{s} \\
\mathbf{h}^{i}
\end{array}\right]+\left[\begin{array}{ll}
\mathbf{H}_{1 a} & \mathbf{H}_{1 b} \\
\mathbf{H}_{1 c} & \mathbf{H}_{1 d}
\end{array}\right]\left[\begin{array}{l}
\mathbf{z}_{t-1}^{s} \\
\mathbf{z}_{t-1}^{i}
\end{array}\right]+\left[\begin{array}{c}
\mathbf{H}_{2 a} \\
\mathbf{H}_{2 b}
\end{array}\right]\left[\begin{array}{c}
\mathbf{u}_{t}^{s} \\
\mathbf{0}
\end{array}\right],
$$

for which the optimal discretionary rule can be written as

$$
\mathbf{x}_{t}=\mathbf{f}+\mathbf{F}_{1 a} \mathbf{z}_{t-1}^{s}+\mathbf{F}_{1 b} \mathbf{z}_{t-1}^{i}+\mathbf{F}_{2 a} \mathbf{u}_{t}^{s} .
$$

Assume that $\mathbf{H}_{2 a}$ has full rank. Let $\mathbf{G}$ be an $n_{s} \times n_{s}$ matrix determined as the solution to $\mathbf{F}_{2 a}-\mathbf{G H}_{2 a}=\mathbf{0}$. By adding and subtracting $\mathbf{G} \mathbf{z}_{t}^{s}$ from equation (12), the shocks, $\mathbf{u}_{t}^{s}$, can be eliminated, allowing the optimal discretionary rule to be expressed as

$$
\mathbf{x}_{t}=\left(\mathbf{f}-\mathbf{G h}^{s}\right)+\left(\mathbf{F}_{1 a}-\mathbf{G H}_{1 a}\right) \mathbf{z}_{t-1}^{s}+\left(\mathbf{F}_{1 b}-\mathbf{G H}_{1 b}\right) \mathbf{z}_{t-1}^{i}+\mathbf{G z}_{t}^{s} .
$$

We now introduce an $n_{s} \times 1$ disturbance vector, $\mathbf{v}_{t}$, to the policy rule to prevent a stochastic singularity from arising during estimation. This disturbance term represents measurement error and is motivated on the realistic and standard assumption that the econometrician estimating the system possesses less information than the policymaker (Hansen and Sargent, 1980).

Using the fact that the time-consistent equilibrium takes the form $\mathbf{z}_{t}=\mathbf{h}+$ $\mathbf{H}_{1} \mathbf{z}_{t-1}+\mathbf{H}_{2} \mathbf{u}_{t}$, the optimization constraints can be expressed as

$$
\left(\mathbf{A}_{0}-\mathbf{A}_{2} \mathbf{H}_{1}\right) \mathbf{z}_{t}=\left(\mathbf{a}+\mathbf{A}_{2} \mathbf{h}\right)+\mathbf{A}_{1} \mathbf{z}_{t-1}+\mathbf{A}_{3} \mathbf{x}_{t}+\mathbf{u}_{t} .
$$


Partitioning $\mathbf{z}_{t}$ as earlier and defining $\mathbf{B}_{0} \equiv \mathbf{A}_{0}-\mathbf{A}_{2} \mathbf{H}, \mathbf{b} \equiv \mathbf{a}+\mathbf{A}_{2} \mathbf{h}, \mathbf{B}_{1} \equiv \mathbf{A}_{1}$, and $\mathbf{B}_{3} \equiv \mathbf{A}_{3}$, equation (14) can be written as

$$
\begin{aligned}
{\left[\begin{array}{ll}
\mathbf{B}_{0 a} & \mathbf{B}_{0 b} \\
\mathbf{B}_{0 c} & \mathbf{B}_{0 d}
\end{array}\right]\left[\begin{array}{l}
\mathbf{z}_{t}^{s} \\
\mathbf{z}_{t}^{i}
\end{array}\right]=} & {\left[\begin{array}{l}
\mathbf{b}^{s} \\
\mathbf{b}^{i}
\end{array}\right]+\left[\begin{array}{ll}
\mathbf{B}_{1 a} & \mathbf{B}_{1 b} \\
\mathbf{B}_{1 c} & \mathbf{B}_{1 d}
\end{array}\right]\left[\begin{array}{l}
\mathbf{z}_{t-1}^{s} \\
\mathbf{z}_{t-1}^{i}
\end{array}\right] } \\
& +\left[\begin{array}{c}
\mathbf{B}_{3 a} \\
\mathbf{B}_{3 b}
\end{array}\right]\left[\mathbf{x}_{t}\right]+\left[\begin{array}{c}
\mathbf{u}_{t}^{s} \\
\mathbf{0}
\end{array}\right]
\end{aligned}
$$

Combining equation (13) with equation (15) gives

$$
\begin{gathered}
{\left[\begin{array}{ccc}
\mathbf{B}_{0 a} & -\mathbf{B}_{3 a} & \mathbf{B}_{0 b} \\
-\mathbf{G} & \mathbf{I} & \mathbf{0} \\
\mathbf{B}_{0 c} & -\mathbf{B}_{3 b} & \mathbf{B}_{0 d}
\end{array}\right]\left[\begin{array}{c}
\mathbf{z}_{t}^{s} \\
\mathbf{x}_{t} \\
\mathbf{z}_{t}^{i}
\end{array}\right]=\left[\begin{array}{c}
\mathbf{b}^{s} \\
\mathbf{f}-\mathbf{G h}^{s} \\
\mathbf{b}^{i}
\end{array}\right]} \\
+\left[\begin{array}{ccc}
\mathbf{B}_{1 a} & \mathbf{0} & \mathbf{B}_{1 b} \\
\mathbf{F}_{1 a}-\mathbf{G H}_{1 a} & \mathbf{0} & \mathbf{F}_{1 b}-\mathbf{G H}_{1 b} \\
\mathbf{B}_{1 c} & \mathbf{0} & \mathbf{B}_{1 d}
\end{array}\right]\left[\begin{array}{c}
\mathbf{z}_{t-1}^{s} \\
\mathbf{x}_{t-1} \\
\mathbf{z}_{t-1}^{i}
\end{array}\right]+\left[\begin{array}{c}
\mathbf{u}_{t}^{s} \\
\mathbf{v}_{t} \\
\mathbf{0}
\end{array}\right] .
\end{gathered}
$$

We now substitute $\mathbf{z}_{t}^{i}$ from the system so that the equations for $\mathbf{z}_{t}^{s}$ and $\mathbf{x}_{t}$ depend only on predetermined, observable, variables, i.e.,

$$
\begin{gathered}
{\left[\begin{array}{cc}
\mathbf{B}_{0 a}-\mathbf{B}_{0 b} \mathbf{B}_{0 d}^{-1} \mathbf{B}_{0 c} & \mathbf{B}_{0 b} \mathbf{B}_{0 d}^{-1} \mathbf{B}_{3 b}-\mathbf{B}_{3 a} \\
-\mathbf{G} & \mathbf{I}
\end{array}\right]\left[\begin{array}{c}
\mathbf{z}_{t}^{s} \\
\mathbf{x}_{t}
\end{array}\right]=\left[\begin{array}{c}
\mathbf{b}^{s}-\mathbf{B}_{0 b} \mathbf{B}_{0 d}^{-1} \mathbf{b}^{i} \\
\mathbf{f}-\mathbf{G h}^{s}
\end{array}\right]} \\
+\left[\begin{array}{cc}
\mathbf{B}_{1 a}-\mathbf{B}_{0 b} \mathbf{B}_{0 d}^{-1} \mathbf{B}_{1 c} & \mathbf{0} \\
\mathbf{F}_{1 a}-\mathbf{G H}_{1 a} & \mathbf{0}
\end{array}\right]\left[\begin{array}{c}
\mathbf{z}_{t-1}^{s} \\
\mathbf{x}_{t-1}
\end{array}\right]+\left[\begin{array}{c}
\mathbf{B}_{1 b}-\mathbf{B}_{0 b} \mathbf{B}_{0 d}^{-1} \mathbf{B}_{1 d} \\
\mathbf{F}_{1 b}-\mathbf{G H}_{1 b}
\end{array}\right]\left[\mathbf{z}_{t-1}^{i}\right]+\left[\begin{array}{c}
\mathbf{u}_{t}^{s} \\
\mathbf{v}
\end{array}\right] .
\end{gathered}
$$

Equation (17) can be written as

$$
\mathbf{C}_{0} \mathbf{y}_{t}=\mathbf{c}+\mathbf{C}_{1} \mathbf{y}_{t-1}+\mathbf{C}_{2} \mathbf{z}_{t-1}^{i}+\boldsymbol{\epsilon}_{t},
$$

where $\mathbf{y}_{t} \equiv\left[\begin{array}{c}\mathbf{z}_{t}^{s} \\ \mathbf{x}_{t}\end{array}\right], \boldsymbol{\epsilon}_{t} \equiv\left[\begin{array}{c}\mathbf{u}_{t}^{s} \\ \mathbf{v}_{t}\end{array}\right]$, and the definitions of $\mathbf{C}_{0}, \mathbf{c}, \mathbf{C}_{1}$, and $\mathbf{C}_{2}$ are straightforward. The model is now in a form to which likelihood-based estimation methods can be applied.

\section{Model Estimates}

In this section we present estimates of the internal-habit-formation and the externalhabit-formation models derived in Section 2. For the internal-habit-formation model, the central bank's optimization problem is constrained by equations (1), (7), and (9), and the parameters to be estimated are $\Gamma=\left\{\beta, \xi_{p}, \sigma, \gamma, \pi^{*}, \lambda, \nu, c^{*}\right\}$. When the habit formation is external, equation (8) replaces equations (7), and we estimate 
$\Gamma=\left\{\beta, \xi_{p}, \sigma, \gamma_{1}, \gamma_{2}, \pi^{*}, \lambda, \nu, c^{*}\right\}$. These two New Keynesian optimal-policy models are estimated on the data discussed in Section 3 over the period 1982.Q1 - 2002.Q2, a period we term the Volcker-Greenspan period for convenience. ${ }^{6}$ Estimates for this period are of broad interest because inflation declined dramatically during this period, and it is important to examine how this disinflation is accounted for within an optimization-based environment. Moreover, simple policy rules estimated over this sample indicate that a systematic and stable approach to monetary policy was pursued, which suggests that monetary policy was not obviously inconsistent with optimal behavior.

\subsection{Estimates with Internal Habit Formation}

With internal habit formation households internalize the effect that consumption today has on the marginal utility of consumption in subsequent periods. Utility maximization yields a consumption Euler equation in which current consumption is affected not only by consumption last period, but also by expected consumption one- and two-periods ahead. The weights on these three consumption terms are determined by $\sigma$, the curvature of the utility function with respect to consumption, and by $\gamma$, the internal-habit-formation parameter.

The estimation results for the five gap variables are presented in Table 2; Panel A presents results for specifications in which the federal funds rate enters the model; Panel B presents estimates based on the 3 -month T-bill rate. ${ }^{7}$

\footnotetext{
${ }^{6}$ Volcker's tenue actually began in 1979.Q3. However, the sample begins in 1982.Q1 to exclude the period of non-borrowed reserves targeting that occurred early in Volcker's tenure.

${ }^{7}$ Where theory dictates that a parameter should be non-negative, the significance levels reported are for one-sided hypothesis tests.
} 


\begin{tabular}{|c|c|c|c|c|c|}
\hline Panel A & \multicolumn{5}{|c|}{ Federal Funds Rate } \\
\hline Parameter & $\widehat{y}_{t}^{1}$ & $\widehat{y}_{t}^{2}$ & $\widehat{y}_{t}^{3}$ & $\widehat{c}_{t}^{1}$ & $\widehat{c}_{t}^{2}$ \\
\hline$\rho$ & $2.61^{\ddagger}$ & $2.67^{\dagger \dagger}$ & $2.81^{\dagger \dagger}$ & $2.43^{\dagger \dagger}$ & $2.49^{\dagger \dagger}$ \\
\hline$\gamma$ & $1.00^{\dagger \dagger}$ & $1.00^{\dagger \dagger}$ & $1.01^{\dagger \dagger}$ & $0.93^{\ddagger}$ & $0.89^{\dagger \dagger}$ \\
\hline $10 \times \frac{1}{\sigma}$ & $0.03^{\dagger}$ & $0.03^{\dagger}$ & $0.04^{\dagger}$ & 0.01 & 0.01 \\
\hline$\xi_{p}{ }^{\circ}$ & $0.92^{\dagger \dagger}$ & $0.86^{\dagger \dagger}$ & $0.83^{\dagger \dagger}$ & $0.82^{\dagger \dagger}$ & $0.78^{\dagger \dagger}$ \\
\hline$\pi^{*}$ & $2.30^{\ddagger}$ & $2.31^{\dagger \dagger}$ & $2.37^{\dagger \dagger}$ & $2.70^{\ddagger}$ & $2.72^{\dagger \dagger}$ \\
\hline$c^{*}$ & 0.05 & 0.07 & 0.06 & 0.05 & 0.04 \\
\hline$\lambda$ & 0.00 & 0.00 & 0.00 & 0.00 & 0.00 \\
\hline$\nu$ & $1.21^{\ddagger}$ & $1.48^{\ddagger}$ & $0.99^{\ddagger}$ & $2.76^{\dagger}$ & $2.06^{\dagger}$ \\
\hline Panel B & \multicolumn{5}{|c|}{ 3-month T-Bill Rate } \\
\hline Parameter & $\widehat{y}_{t}^{1}$ & $\widehat{y}_{t}^{2}$ & $\widehat{y}_{t}^{3}$ & $\widehat{c}_{t}^{1}$ & $\widehat{c}_{t}^{2}$ \\
\hline$\rho$ & $2.10^{\dagger}$ & $2.27^{\dagger \dagger}$ & $2.41^{\dagger \dagger}$ & $2.04^{\dagger \dagger}$ & $2.12^{\dagger \dagger}$ \\
\hline$\gamma$ & $1.00^{\dagger \dagger}$ & $1.00^{\dagger \dagger}$ & $1.01^{\dagger \dagger}$ & $0.91^{\dagger \dagger}$ & $0.88^{\dagger \dagger}$ \\
\hline $10 \times \frac{1}{\sigma}$ & $0.02^{\dagger}$ & $0.03^{\dagger}$ & $0.04^{\dagger}$ & 0.01 & 0.01 \\
\hline$\xi_{p}$ & $0.92^{\dagger \dagger}$ & $0.87^{\dagger \dagger}$ & $0.84^{\dagger \dagger}$ & $0.83^{\dagger \dagger}$ & $0.79^{\dagger \dagger}$ \\
\hline$\pi^{*}$ & $2.23^{\ddagger}$ & $2.27^{\dagger \dagger}$ & $2.34^{\dagger \dagger}$ & $2.69^{\ddagger}$ & $2.71^{\dagger \dagger}$ \\
\hline$c^{*}$ & 0.07 & 0.08 & 0.06 & 0.05 & 0.04 \\
\hline$\lambda$ & 0.00 & 0.00 & 0.00 & 0.00 & 0.00 \\
\hline$\nu$ & $1.72^{\ddagger}$ & $2.14^{\ddagger}$ & $1.42^{\ddagger}$ & $4.05^{\dagger}$ & $2.83^{\dagger}$ \\
\hline \multicolumn{6}{|c|}{$\begin{array}{l}+\dagger \text { indicates significance at the } 1 \% \text { level } \\
\ddagger \text { indicates significance at the } 5 \% \text { level } \\
\dagger \text { indicates significance at the } 10 \% \text { level }\end{array}$} \\
\hline
\end{tabular}

Looking first at the results in Panel A, the estimates of the rate of time preference, $\rho(\rho=-\ln (\beta))$, which is the same as the equilibrium, or steady-state, real interest rate in this model, range between 2.43 and 2.81, implying estimates of $\beta$ that are between 0.993 and 0.994 . These estimates of $\beta$ are consistent with conventional values in quarterly models. In theory, the habit-formation parameter, $\gamma$, should be less than one. Perhaps surprisingly, the estimates of $\gamma$ in Table 2 that are based on output data are all slightly greater than one, but in no case are they significantly different from one. More importantly, in each case, $\gamma$ is significantly different from zero, providing evidence for the view that the standard time-separable utility function cannot adequately describe consumption/output dynamics. For the specifications estimated on consumption data $\gamma$ is estimated to be about 0.90 . Other estimates of habit formation, such as those in Fuhrer (2000, Table 1), $\gamma=0.80,0.90$, also impart significant inertia in consumption, while coming from a slightly different specification for habit formation. 
The parameter $\frac{1}{\sigma}$, which relates to the curvature of the utility function with respect to consumption, is found to be very small numerically, although statistically significant for the output-based estimations. Such small values for $\frac{1}{\sigma}$ suggest that households are relatively unwilling to substitute consumptiuon through time. Campbell and Mankiw (1989) estimate $\frac{1}{\sigma}$ to be about ?.??, as does Ireland (1997), while Kim (2000) finds it to be 0.07 .

On the supply side, across the output gap measures we find that between $8-17$ percent of firms re-optimize their price each period, implying a large degree of price "stickiness." The estimate of $\xi_{p}$ declines to around 0.80 when the model is estimated on the consumption gap variables. Galí and Gertler (1999, Table 1), estimate $\xi_{p}$ to be between 0.83 and 0.92 for the US, thus our estimates are consistent with their findings.

Turning to the policy regime parameters, the implicit inflation target, $\pi^{*}$, is estimated to be between 2.30 percent and 2.72 percent. The estimates of $\pi^{*}$ are slightly lower when the model is estimated on GDP-price-index inflation than when estimated on core-PCE inflation. With inflation measured using the GDP price index, Dennis (2003) estimates $\pi^{*}$ to be 2.43 percent and Favero and Rovelli (2003) estimate it to be 2.63 percent. For all five output/consumption gap variables, the relative weight that the Federal Reserve places on output stabilization, $\lambda$, is small and statistically insignificant. A wide range of values for $\lambda$ have been obtained in the literature, with estimates ranging between $\lambda=0.001$ (Favero and Rovelli, 2003) and $\lambda=4.56$ (Söderlind, 1999), but most estimates place $\lambda$ between zero and one. The interest rate smoothing parameter, $\nu$, is significant for each gap variable, with the estimates themselves ranging between 0.99 and 2.76. These point estimates are consistent with the results in Dennis (2003), who gets $\nu=1.95$ (using $\widehat{y}_{t}^{1}$ as the output gap), and with the calibration results in Söderlind, Söderström, and Vredin (2002). In addition, for each specification $c^{*}$ is not significantly different from zero, supporting the view that Federal Reserve behavior did not generate a discretionary inflation bias (Blinder, 1998).

When the model is estimated on the 3-month T-bill rate, the parameter estimates are largely unaffected. However, two important differences are evident. First, while the estimates of the implicit inflation target do not change much, the lower average 
value for the 3-month T-bill rate translates into a lower estimate of the rate of time preference or, equivalently, into a higher estimate of the subjective discount factor. Second, when the model is estimated on the 3-month T-bill rate, noticeably larger estimates of $\nu$, the relative weight policymakers place on interest rate smoothing, are obtained.

\subsection{Estimates with External Habit Formation}

The previous subsection presented model estimates for the case where households internalize the habit formation into their decision making. In this subsection, we present estimates under the assumption that the habit formation is external. For this exercise, the habit stock is assumed to depend on two lags of consumption, namely

$$
H_{t}=\gamma_{1} C_{t-1}+\gamma_{2} C_{t-2}, \quad\left|\gamma_{1}+\gamma_{2}\right|<1
$$

where equation (19) is motivated on the stylized fact that reduced-form equations for the output gap typically depend on two lags of the output gap (King, Plosser, Stock, and Watson, 1991; Galí, 1992). Expressing the habit formation according to equation (19), rather than according to the simpler specification that has $\gamma_{2}=0$, leads to a system whose equilibrium relationships can contain two lags of the gap, placing the model on a better footing to fit the data. For this reason, if this two-lag specification for habit formation fails to describe the dynamics of output/consumption, then this amounts to a more powerful strike against the New Keynesian optimal-policy apparatus. Estimates of the model with external habit formation are presented in Table 3. 


\begin{tabular}{|c|c|c|c|c|c|}
\hline Panel A & \multicolumn{5}{|c|}{ Federal Funds Rate } \\
\hline Parameter & $\widehat{y}_{t}^{1}$ & $\widehat{y}_{t}^{2}$ & $\widehat{y}_{t}^{3}$ & $\widehat{c}_{t}^{1}$ & $\widehat{c}_{t}^{2}$ \\
\hline$\rho$ & $4.26^{\dagger}$ & 2.47 & 1.99 & $3.12^{\dagger \dagger}$ & $3.35^{\ddagger}$ \\
\hline$\gamma_{1}$ & $1.58^{\dagger \dagger}$ & $1.38^{\dagger \dagger}$ & $1.26^{\dagger \dagger}$ & $0.96^{\dagger \dagger}$ & $0.98^{\dagger \dagger}$ \\
\hline$\gamma_{2}$ & $-0.68^{\dagger \dagger}$ & $-0.54^{\dagger \dagger}$ & $-0.44^{\ddagger}$ & -0.08 & -0.14 \\
\hline$\frac{1}{\sigma}$ & $0.05^{\dagger}$ & 0.02 & 0.02 & 0.02 & 0.01 \\
\hline$\xi_{p}$ & $0.86^{\dagger \dagger}$ & $0.77^{\dagger \dagger}$ & $0.76^{\dagger \dagger}$ & $0.81^{\dagger \dagger}$ & $0.75^{\dagger \dagger}$ \\
\hline$\pi^{*}$ & $2.82^{\ddagger}$ & $2.27^{\dagger}$ & 2.11 & $3.01^{\dagger \dagger}$ & $3.12^{\dagger \dagger}$ \\
\hline$c^{*}$ & 0.17 & -0.07 & -0.21 & 0.25 & 0.23 \\
\hline$\lambda$ & 0.15 & 0.88 & 0.75 & 0.00 & 0.61 \\
\hline$\nu$ & $0.44^{\ddagger}$ & $0.79^{\ddagger}$ & $0.73^{\ddagger}$ & $3.36^{\dagger}$ & $2.50^{\dagger}$ \\
\hline Panel B & \multicolumn{5}{|c|}{ 3-month T-Bill Rate } \\
\hline Parameter & $\widehat{y}_{t}^{1}$ & $\widehat{y}_{t}^{2}$ & $\widehat{y}_{t}^{3}$ & $\widehat{c}_{t}^{1}$ & $\widehat{c}_{t}^{2}$ \\
\hline$\rho$ & $3.61^{\ddagger}$ & 2.21 & 2.04 & $2.53^{\dagger \dagger}$ & $2.80^{\ddagger}$ \\
\hline$\gamma_{1}$ & $1.59^{\dagger \dagger}$ & $1.40^{\dagger \dagger}$ & $1.29^{\dagger \dagger}$ & $0.93^{\dagger \dagger}$ & $0.97^{\dagger \dagger}$ \\
\hline$\gamma_{2}$ & $-0.70^{\dagger \dagger}$ & $-0.57^{\dagger \dagger}$ & $-0.48^{\ddagger}$ & -0.05 & -0.13 \\
\hline$\frac{1}{\sigma}$ & $0.05^{\dagger}$ & $0.02^{\dagger}$ & 0.02 & 0.03 & 0.01 \\
\hline$\xi_{p}$ & $0.85^{\dagger \dagger}$ & $0.75^{\dagger \dagger}$ & $0.74^{\dagger \dagger}$ & $0.82^{\dagger \dagger}$ & $0.75^{\dagger \dagger}$ \\
\hline$\pi^{*}$ & $2.84^{\dagger \dagger}$ & $2.30^{\dagger}$ & 2.23 & $2.95^{\dagger \dagger}$ & $3.11^{\dagger \dagger}$ \\
\hline$c^{*}$ & 0.17 & -0.05 & -0.10 & 0.24 & 0.23 \\
\hline$\lambda$ & 0.17 & 1.04 & 1.21 & 0.00 & 0.00 \\
\hline$\nu$ & $0.60^{\ddagger}$ & $1.02^{\ddagger}$ & $0.91^{\ddagger}$ & $4.97^{\dagger}$ & $3.40^{\dagger}$ \\
\hline \multicolumn{6}{|c|}{$\begin{array}{l}+\dagger \text { indicates significance at the } 1 \% \text { level } \\
\ddagger \text { indicates significance at the } 5 \% \text { level } \\
\dagger \text { indicates significance at the } 10 \% \text { level }\end{array}$} \\
\hline
\end{tabular}

Table 3 shows that the second parameter in the external habit formation process, $\gamma_{2}$, is significantly different from zero only when the model is estimated on the output gap variables. For these output-gap-based specifications, the negative sign on $\gamma_{2}$ makes it natural to represent the habit formation process as

$$
H_{t}=\left(\gamma_{1}+\gamma_{2}\right) C_{t-1}-\gamma_{2} \Delta C_{t-1}
$$

which implies that the marginal utility of consumption is declining in both the level and the growth rate of last period's consumption. However, if the dynamics in equation (20) truly reflect habit formation, then we would expects a similar dynamic structure to be present when the model is estimated on consumption data. Yet, when the model is estimated on either $\widehat{c}_{t}^{1}$ or $\widehat{c}_{t}^{2}, \gamma_{2}$ is not significantly different from zero. The finding that $\gamma_{2}$ is significant in the output-based specifications, but not in 
the consumption-based specifications, suggests a problem with the underlying model, whose resource constraint equates output to consumption. While the parameter restriction $-\left|\gamma_{1}+\gamma_{2}\right|<1$ - is satisfied for all specifications, the estimates point to the fact that the dynamics of consumption and output are very different.

The fact that the differences between the output-based and the consumptionbased estimates of $\gamma_{1}$ and $\gamma_{2}$ are systematic across the datasets implies that they are not simply a consequence of the filtering process used to de-trend output. Several factors could account for the differences between the output-based and the consumption-based estimates, but perhaps the most obvious candidate is investment and the process of capital formation. Both the canonical New Keynesian model and standard generalizations of the canonical model (such as those estimated here) abstract from investment, partly as a simplifying device, but also on the basis that the long-run effects of capital formation can be put aside to analyze short-run macroeconomic stabilization issues. Problems with measuring the capital stock also make it difficult to estimate models that allow for capital accumulation. The results above highlight the fact that abstracting from investment may mean that an important mechanism through which shocks are propagated is omitted. If this is the case, then the results in Dupor (2001), which emphasize that policy rules that satisfy the Taylor principle produce indeterminacy in models with investment, suggest that ignoring investment could have important implications for how monetary policy should be set.

Looking at the other parameter estimates, similar to the internal-habit-formation specifications, with external habit formation the implicit inflation target is estimated to be between 2.11 percent and 3.12 percent, the subjective discount factor is estimated to be between 0.989 and 0.995 , and the Calvo-pricing parameter is estimated to be between 0.74 and 0.86 . Larger point estimates of $\frac{1}{\sigma}$ are obtained from the external habit formation specifications, but these estimates tend to be insignificant, especially when the model is estimated on consumption data.

Turning to the other parameters in the policy objective function, the results are similar to those obtained with internal habit formation. The relative weight on interest rate smoothing is significantly different from zero, but the weight on output/consumption stabilization is insignificant and there is no evidence of a discretionary inflation bias. While the point estimates of $\nu$ are, in general, smaller for 
the external-habit-formation model than for the internal-habit-formation model, as found earlier, the weight placed on interest rate smoothing is larger when the model is estimated on the 3-month T-bill than when it is estimated on the federal funds rate.

\section{How well do the Models Fit the Data?}

The estimates in Section 4 reveal both successes and failures with the New Keynesian optimal-policy apparatus. In particular, while all of the models' parameters have the correct sign, the estimates of $\beta$ and the implicit inflation target are very plausible, and a significant weight on interest rate smoothing is found, $\frac{1}{\sigma}$ is small and often statistically insignificant, the point estimates of $\gamma$, in the internalhabit-formation specifications, are greater than one for the output-based estimations, and the relative weight policymakers place on output/consumption stabilization is small and/or statistically insignificant. Furthermore, the finding that the properties of the external-habit process differ importantly between the output-based and the consumption-based specifications - when the model's resource constraint stipulates equivalence - suggests that an important source of dynamics may be missing from the model. As discussed above, since the omitted factor produces second-order dynamics in the output-based specifications, but not in the consumption-based specifications, a likely candidate for this omitted factor is investment. The fact that $\gamma$ tends to be slightly above one when the internal-habit-formation model is estimated on output data, but comfortably below one when the model is estimated on consumption data, lends further support to the view that some source of dynamics is omitted from the output-based specifications.

Because the hybrid New Keynesian models are significantly better empirically than the canonical model, we now examine whether these hybrid New Keynesian models provide an adequate description of US data. To assess their performance, each specification is compared to exactly identified $\operatorname{VAR}(1), \operatorname{VAR}(2)$, and $\operatorname{VAR}(4)$ processes. Three lag lengths are used when estimating the VARs because the equilibrium of the internal-habit-formation model is nested within a $\operatorname{VAR}(1)$, the equilibrium of the external-habit-formation model is nested within a $\operatorname{VAR}(2)$, and many popular backward-looking models, such as the Rudebusch-Svensson model, are nested 
within a VAR(4). For each dataset, for each model, and for each VAR, the Akaike information criterion (Akaike, 1973), the Bayesian Schwarz criterion (Schwarz, 1978), and the Hannan-Quinn criterion (Hannan and Quinn, 1979) are computed. For each specification, Table 4 presents the values of the three information criteria, relative to the corresponding values from the three VARs. Values for the relative information criteria that are less than one lend support for the theoretical models while values greater than one support the unrestricted models over the theoretical models.

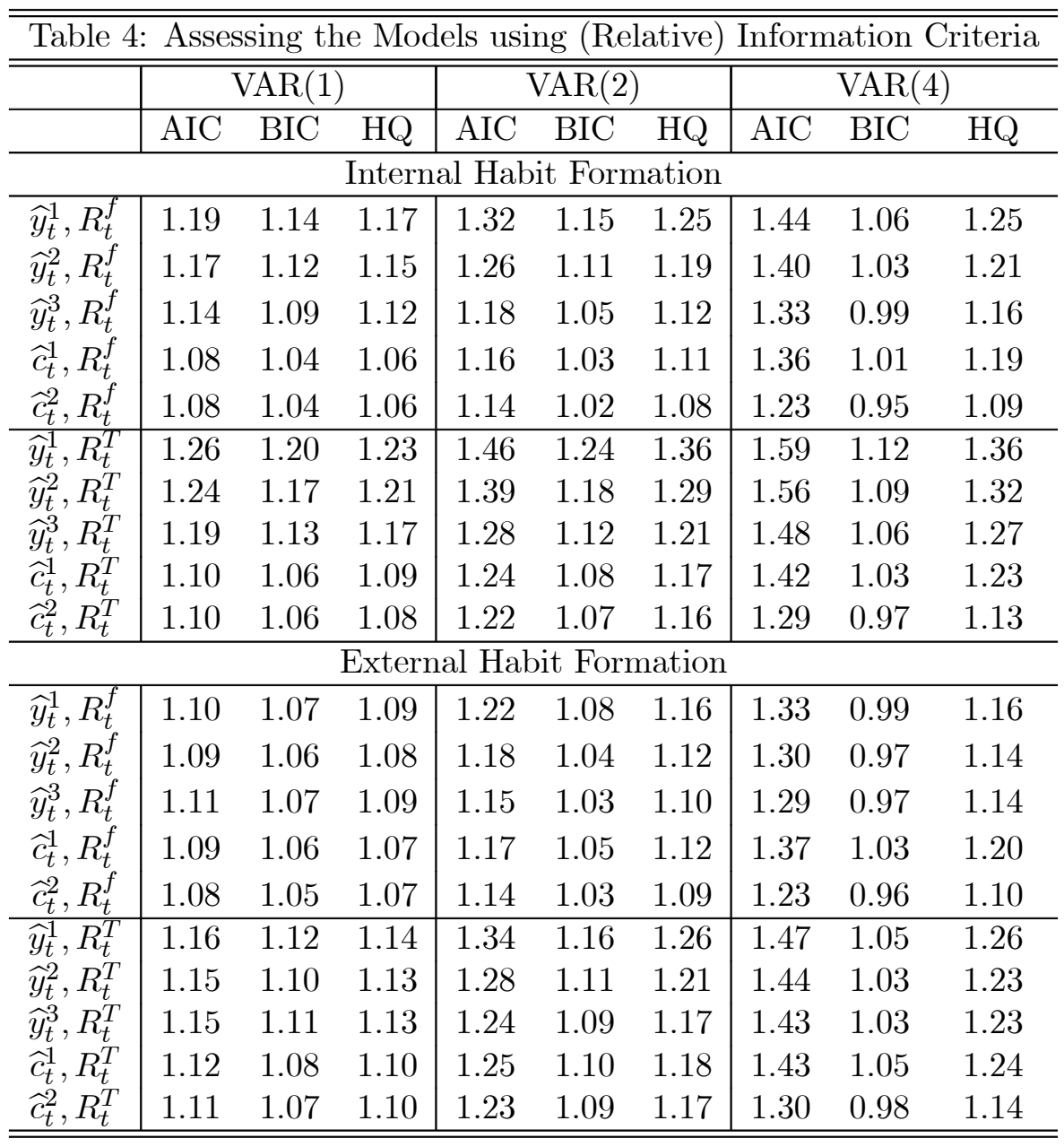

Table 4 shows that regardless of the VAR's lag length, and regardless of the particular information criterion used, the New Keynesian optimal-policy models do not fit the data as well as the VARs according to these information criteria. Only when the models are compared to a VAR(4) process using the BIC criterion, which places the largest penalty on parameter-number, are there any cases for which the 
relative information criteria are less than one. Thus, although the VARs are penalized for containing a much larger number of parameters, they still tend to out-perform the New Keynesian specifications.

Three other interesting results emerge from Table 4. First, on average, the specifications with external habit formation perform better than those with internal habit formation. This suggests that further development of New Keynesian models might usefully employ external habit formation, especially for empirical applications. Second, the New Keynesian models estimated on $\widehat{y}_{t}^{1}$ perform the worst. This indicates that the $\mathrm{CBO}$ measure of potential output may be introducing dynamics into the output gap that can be accommodated within the VAR models, which have lots of parameters, but not within more tightly parameterized theoretical specifications. Looking at Figure 1A, it is clear that the characteristics of $\widehat{y}_{t}^{1}$ are different to those of $\widehat{y}_{t}^{2}$ or $\widehat{y}_{t}^{3}$; the results in Table 4 establish that these characteristics cannot easily be accounted for within the confines of New Keynesian optimal-policy models. Thirdly, estimating the models on $\widehat{c}_{t}^{2}$ produces the best overall results in the sense that the resulting specifications perform best relative to the VAR models. Since $\widehat{c}_{t}^{2}$ is constructed by normalizing consumption with respect to the size of the labor force, this implies that estimating New Keynesian models on consumption data and taking the representative household assumption seriously may be important.

\subsection{Impulse Response Functions}

When assessed according to the three information criteria, the models performed best when estimated on consumption per head, $\widehat{c}_{t}^{2}$, and on the federal funds rate, $R_{t}^{f}$ (but only marginally better than specification estimated on $R_{t}^{T}$ ). To present the best case for the New Keynesian optimal-policy framework we use the models estimated on $\widehat{c}_{t}^{2}, \pi_{t}^{c}$, and $R_{t}^{f}$ and compare their impulse responses to those from the VAR(4) model estimated on the same data. From this VAR model we also construct 95 percent confidence bands about the VAR impulse responses. Notably, Table 4 indicates that the internal-habit-formation specification performs slightly better than the external-habit-formation specification for this dataset.

Comparing the impulse response functions from the New Keynesian models to those from the VAR helps to identify areas where the New Keynesian models fail 
to adequately reflect the data. For the VAR the impulse response functions are generated for "supply", "demand", and "policy" shocks, using a recursive identification scheme with inflation ordered first and the federal funds rate ordered last. It is clear, however, that the New Keynesian optimal-policy models are not recursive. Thus, to ensure that a valid comparison of the impulse response functions is made, we identify the shocks in the New Keynesian models by placing the variables in the same order as in the VAR and by imposing the same recursive identification scheme. To be specific, we take the time-consistent equilibrium of the New Keynesian models, which can both be represented within

$$
\mathbf{D}_{0} \mathbf{p}_{t}=\mathbf{d}+\mathbf{D}_{1} \mathbf{p}_{t-1}+\mathbf{D}_{2} \mathbf{p}_{t-2}+\mathbf{s}_{t}
$$

where $\mathbf{p}_{t}=\left[\begin{array}{ccc}\widehat{c}_{t}^{2} & \pi_{t}^{c} & R_{t}^{f}\end{array}\right]^{\prime}$, where $\mathbf{s}_{t} \sim N[\mathbf{0}, \boldsymbol{\Omega}]$, and where $\mathbf{D}_{0}$ has full rank, but is not lower triangular. Premultiplying equation (21) by $\mathbf{D}_{0}^{-1}$ gives

$$
\mathbf{p}_{t}=\mathbf{k}+\mathbf{K}_{1} \mathbf{p}_{t-1}+\mathbf{K}_{2} \mathbf{p}_{t-2}+\boldsymbol{\omega}_{t}
$$

where $\boldsymbol{\omega}_{t} \sim N\left[\mathbf{0}, \mathbf{D}_{0}^{-1} \boldsymbol{\Omega} \mathbf{D}_{0}^{\prime-1}\right] . \quad$ Let $\mathbf{M}_{0}^{-1} \mathbf{M}_{0}^{\prime-1}=\mathbf{D}_{0}^{-1} \mathbf{\Omega} \mathbf{D}_{0}^{\prime-1}$, where $\mathbf{M}_{0}^{\prime-1}$ is an upper triangular matrix constructed using a Choleski decomposition, then premultiplying equation (22) by $\mathbf{M}_{0}$ gives

$$
\mathbf{M}_{0} \mathbf{z}_{t}=\mathbf{m}+\mathbf{M}_{1} \mathbf{z}_{t-1}+\mathbf{M}_{2} \mathbf{z}_{t-2}+\varepsilon_{t}
$$

Because $\mathbf{M}_{0}^{\prime-1}$ is upper triangular, $\mathbf{M}_{0}$ is lower triangular, and equation (23) is in the form of a recursively identified structural VAR. Transformed in this way the impulse responses from the New Keynesian models can be compared to those from the recursively identified VAR. Impulse response functions for shocks to the inflation and consumption equations - "demand" and "supply" shocks - are shown in Figure 2 .

Looking at the impulse responses from the $\operatorname{VAR}(4)$ process, following a one standard deviation demand shock consumption rises, inflation increases and monetary policy is tightened. In response to higher interest rates, consumption and inflation both begin to decline, eventually returning to baseline. For the supply shock, the VAR reveals that inflation rises and that interest rates are raised in response. Higher interest rates cause consumption to fall below baseline. With higher interest rates 
Ponel A: Consumption Response

Demand Shock

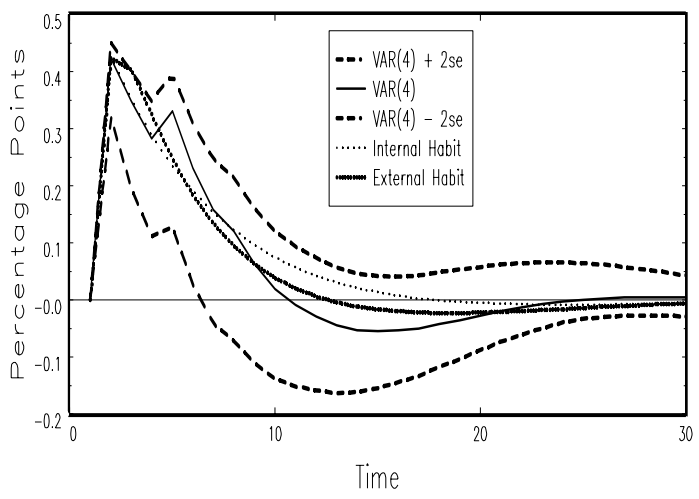

Ponel C: Inflation Responses

Demand Shock

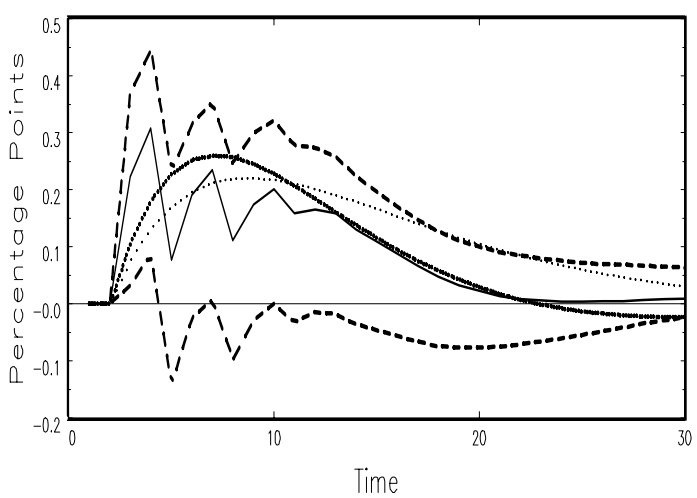

Panel E: Interest Rate Responses

Demand Shock

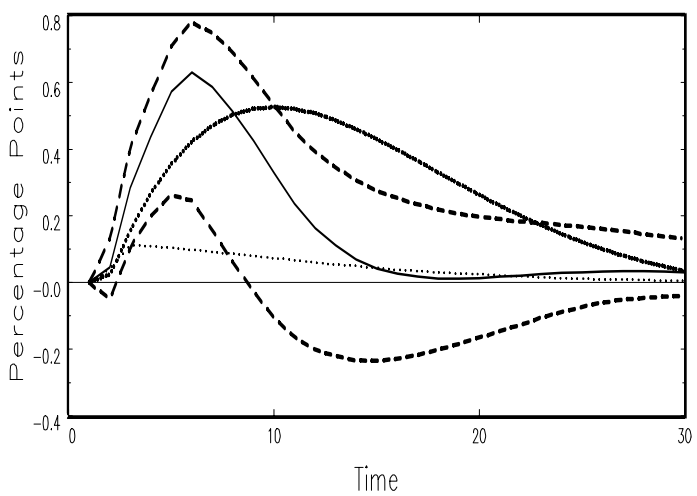

Panel B: Consumption Response

Supply Shock

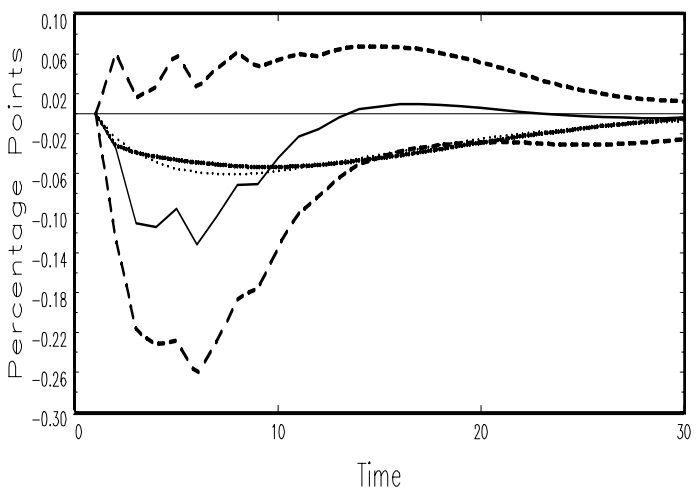

Panel D: Inflation Responses

Supply Shock

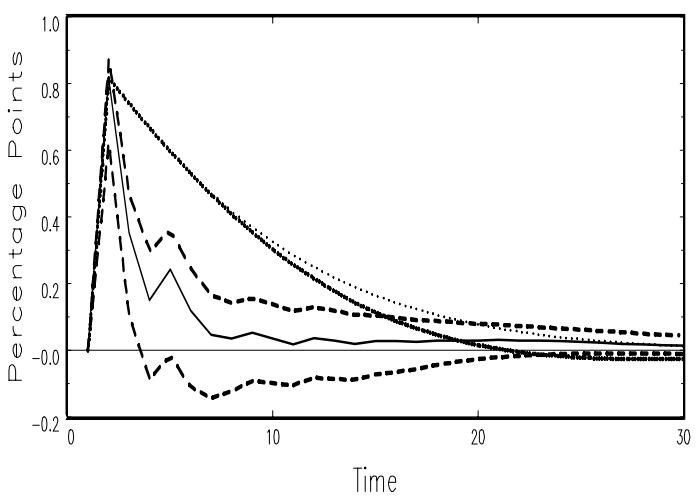

Ponel F: Interest Rate Responses

Supply Shock

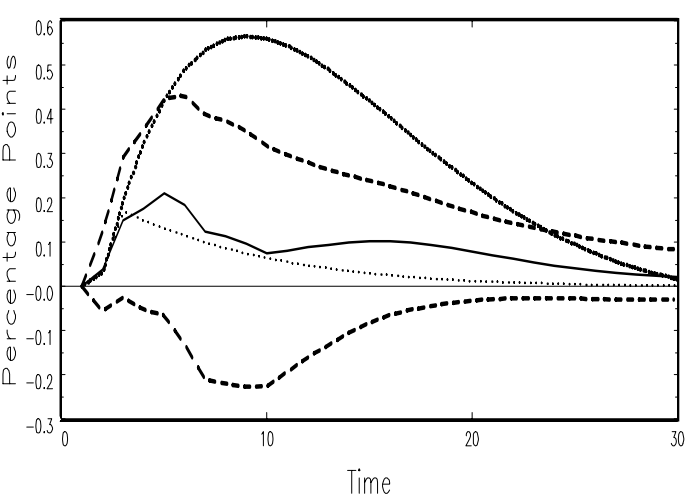

Figure 2: Impulse Response Functions 
and lower consumption, inflation begins to fall. As inflation falls, interest rates decline and consumption begins to rise back to baseline.

Qualitatively, the impulse responses from the two New Keynesian models are similar to those from the VAR model. In response to a one standard deviation demand shock, consumption rises and the increase in consumer demand places pressure on firms to increase prices. As an increasing number of firms raise their price, inflation begins to rise and the central bank responds by tightening policy and increasing the interest rate. For the internal-habit-formation model, the demand shock leads to a relatively muted interest rate response because policymakers place little or no weight on consumption stabilization. For the external-habit-formation model, however, the estimated weight on consumption stabilization leads to a rapid increase in interest rates following the shock. By-and-large, the impulse responses from the internalhabit-formation model and the external-habit-formation model are both similar to those from the VAR(4), and they typically lie inside the VAR's 95 percent confidence bands. However, both New Keynesian models have difficulty capturing the interest rate's response to the demand shock, with both model's responses violating the 95 percent confidence band.

Turning to the impulse responses for the supply shock, inflation rises following the shock causing the central bank to raise the interest rate. The rise in interest rates causes consumption to fall, with the associated drop in aggregate demand placing downward pressure on inflation. When the impulse response functions from the two New Keynesian models are compared to those from the VAR, it is clear that the greatest discrepancies lie in how inflation evolves following the supply shock. The assumption that non-optimizing firms index their price level to last period's inflation rate appears to make inflation excessively persistent. Because of this persistence in inflation, the interest rate response to the supply shock for the external-habitformation specification is also very large, far exceeding the VAR's response.

For this particular dataset, the internal habit formation model and the external habit formation model produce similar impulse responses, and these impulse responses are often similar to those from the VAR(4) process. However, both New Keynesian models have difficulty capturing how interest rates respond to shocks and how inflation responds to supply shocks. Specifically, when compared to the VAR's 
impulse responses, inflation is excessively persistent.

\section{Conclusion}

This paper has examined whether the New Keynesian optimal-policy models that are widely analyzed in the optimal monetary policy literature provide an empirically adequate description of US economic outcomes for the Volcker-Greenspan period. It is well known that the canonical New Keynesian model, while being analytically tractable, has little empirical content and performs badly when assessed against actual outcomes. It is also well known that the central problem with the canonical model is that it contains no endogenous dynamics, no mechanism to generate the persistence observed in US data. For this reason, much of the optimal monetary policy rules literature has moved away from the canonical model, turning instead to generalized, or hybrid, specifications in which inflation indexation and habit formation introduce endogenous inflation and output/consumption dynamics.

In this paper two popular hybrid New Keynesian models are estimated and analyzed to assess how well they fit US data. Both models have Calvo-pricing and inflation indexation by non-optimizing firms, but whereas one model has internal habit formation the other has external habit formation. Both models are closed with the assumption that monetary policy is set according to an optimal discretionary rule, an assumption that allows the central bank's implicit inflation target and the relative weights assigned to target variables in the policy objective function to be identified and estimated. These policy objective function parameters are estimated alongside the behavioral parameters in the models. Several datasets are used for estimation and the resulting parameter estimates are interpreted in light of the underlying theory and in light of the existing empirical literature. To determine whether the models provide an adequate description of US economic dynamics, and to establish the dimensions along which the models are deficient, each model is assessed against several VARs.

The key results that emerge from the analysis are as follows. First, the estimates of the implicit inflation target and of the subjective discount factor are relatively robust across models and across datasets. When inflation is measured using the GDP

chain-weighted price index, estimates of the implicit inflation target range between 
2.11 percent and 2.84 percent; estimates using core-PCE price inflation vary between 2.69 percent and 3.12 percent. Estimates of the implicit inflation target are largely unaffected by whether the instrument for monetary policy is the federal funds rate or the 3-month T-bill rate. The subjective discount factor is estimated to be between 0.989 and 0.995 , a range that is consistent with assumed values in quarterly models.

Second, we do not find evidence that US policymakers have attempted to use monetary policy to permanently boost output above the economy's potential. For both New Keynesian models, and for all datasets considered, estimates of the discretionary inflation bias are small and/or statistically insignificant. We find significant evidence that policymakers smooth interest rates, but no evidence for an output/consumption stabilization objective, both findings that are consistent with other studies. Larger point estimates of the interest rate smoothing parameter are obtained when the models are estimated on consumption data and when the models are estimated on the 3-month T-bill rate.

Third, allowing for some form of habit formation significantly improves the models' ability to fit the data. The estimates of the habit formation parameters are highly significant, implying that the standard time-separable utility function is too rigid for empirical applications. Estimates of the internal-habit-formation parameter are around one (but are not significantly different from one) for output-based estimations, but comfortably within for the consumption-based estimations. For the external-habit-formation model we also find important differences in the parameter estimates depending on which dataset the model is estimated on. When the externalhabit-formation model is estimated on output data, two lags of output are statistically significant in the habit stock process. The coefficient signs on these two lags imply that the marginal utility of consumption is lowered by increases in both the level and the growth rate of last period's consumption. In contrast, when the model is estimated on consumption data, only one lag of consumption is found to be significant in the habit stock process. These differences between the output-based estimates and the consumption-based estimates across both the internal- and external-habitformation specifications suggest that some alternative source of dynamics may be at work. A likely source for these dynamics is investment in physical capital, a vehicle for savings that is abstracted from in most New Keynesian optimal-policy models. 
Fourth, estimates of the Calvo-pricing parameter, which determines the proportion of firms that are able to re-optimize their price each period, indicate significant price "stickiness." The point estimates of the Calvo-pricing parameter, which are between 0.74 and 0.92 (indicating that between 8 percent and 26 percent of firms reset their price each quarter), are consistent with other estimates. Greater price flexibility is evident for the external-habit-formation specifications. Fifth, according to standard information criteria, the New Keynesian models do not fit the data as well as exactly identified VAR processes do. However, specifications that are estimated on consumption data perform better than those estimated on output data; an intriguing result given that most New Keynesian models are applied and interpreted in terms of output gap specifications. Focusing on the dataset for which the models perform best, when the impulse response functions from the New Keynesian models are compared to those from a $\operatorname{VAR}(4)$ model it is apparent that both New Keynesian models have difficulty capturing the economy's response to supply shocks and how interest rates respond to either demand or supply shocks. Importantly, looking across the different estimations, the external-habit-formation model appears to fit the data slightly better than the internal-habit-formation model. This result suggests that developing the New Keynesian optimal-policy model by building on external habit formation, rather than on internal habit formation, may be the more promising way forward.

Overall, while the hybrid New Keynesian models estimated in this paper do offer a statistically significant improvement over the canonical model, they are still deficient in several important respects, and are outperformed by VAR models, even when the VAR models are penalized for being over-parameterized. Better results are achieved when the models are estimated on consumption data and when external habit formation is employed. However, the absence of investment from the New Keynesian optimal-policy model appears to be a serious shortcoming, particularly because the design of optimal policy rules can hinge importantly on whether or not capital formation takes place. Adding investment and allowing capital to be a productive input is an important area for future work. 


\section{References}

[1] Akaike, A., (1973), "Information Theory and the Extension of the Maximum Likelihood Principle," in Petrov, B., and Csaki, F., (eds) 2nd International Symposium on Information Theory, Akailseoniai-Kiudo, Budapest, pp267-281.

[2] Amato, J., and T. Laubach, (2003), "Implications of Habit Formation for Optimal Monetary Policy," Journal of Monetary Economics, forthcoming.

[3] Blinder, A., (1998), Central Banking in Theory and Practice, MIT Press, Cambridge, Massachusetts.

[4] Bryant, R., Hooper, P., and C. Mann, (1993), Evaluating Policy Regimes: New Results in Empirical Macroeconomics, The Brookings Institution, Washington.

[5] Calvo, G., (1983), "Staggered Contracts in a Utility-Maximising Framework," Journal of Monetary Economics, 12, pp383-398.

[6] Campbell, J., and G. Mankiw, (1989), "Consumption, Income, and Interest Rates: Reinterpreting the Time Series Evidence," in Blanchard, O., and S. Fischer, (eds) NBER Macroeconomics Annual 1989, MIT Press, Cambridge.

[7] Christiano, L., Eichenbaum, M., and C. Evans, (2001), "Nominal Rigidities and the Dynamic Effects of a Shock to Monetary Policy," Northwestern University, mimeo (May, 2001).

[8] Clarida, R., Galí, J., and M. Gertler, (1999), "The Science of Monetary Policy: A New Keynesian Perspective," Journal of Economic Literature, 37, 4, pp16611707.

[9] Dennis, R., (2001), "The Policy Preferences of the US Federal Reserve," Federal Reserve Bank of San Francisco Working Paper \#2001-19 (June, 2003).

[10] Dennis, R., (2003), "Inferring Policy Objectives from Economic Outcomes," Federal Reserve Bank of San Francisco Working paper \#2003-05 (July, 2003).

[11] Dupor, B., (2001), "Investment and Interest Rate Policy," Journal of Economic Theory, 98, 1, pp85-113.

[12] Erceg, C., Henderson, D., and A. Levin, (2000), "Optimal Monetary Policy with Staggered Wage and Price Contracts," Journal of Monetary Economics, 46, pp281-313.

[13] Estrella, A., and J. Fuhrer, (2002), "Dynamic Inconsistencies: Counterfactural Implications of a Class of Rational-Expectations Models," American Economic Review, 92, 4, pp1013-1028.

[14] Favero, C., and R. Rovelli, (2003), "Macroeconomic Stability and the Preferences of the Fed. A Formal Analysis, 1961-98," Journal of Money Credit and Banking, forthcoming.

[15] Fuhrer, J., (2000), "Optimal Monetary Policy in a Model with Habit Formation," American Economic Review, 90, 3, pp367-390.

[16] Fuhrer, J., and G. Rudebusch, (2002), "Estimating the Euler Equation for Output," Federal Reserve Bank of San Francisco Working Paper \#2002-12 (September, 2002). 
[17] Galí, J., (1992), "How Well does the IS-LM Model fit Postwar U.S. Data?," Quarterly Journal of Economics, May, pp709-738.

[18] Galí, J., and M. Gertler, (1999), "Inflation Dynamics: A Structural Econometric Analysis," Journal of Monetary Economics, 44, pp195-222.

[19] Galí, J., and T. Monacelli, (2000), "Optimal Monetary Policy and Exchange Rate Volatility in a Small Open Economy," Universitat Pompeu Fabra, mimeo (May, 2000).

[20] Goodfriend, M., and R. King, (1997), "The New Neoclassical Synthesis and the Role of Monetary Policy," in Bernanke, B., and J. Rotemberg (eds) NBER Macroeconomic Annual 1997, MIT Press, Cambridge, MA, pp231-283.

[21] Hannan, E., and B. Quinn, (1979), "The Determination of the Order of an Autoregression," Journal of the Royal Economic Society, Series B, 41, pp190195.

[22] Hansen, L., and T. Sargent, (1980), "Formulating and Estimating Dynamic Linear Rational Expectations Models," Journal of Economic Dynamics and Control, $2, \mathrm{pp} 7-46$.

[23] Ireland, P., (1997), "A Small, Structural, Quarterly Model for Monetary Policy Evaluation," Carnegie-Rochester Conference Series on Public Policy, 47, pp83108.

[24] Jensen, H., (2002), "Targeting Nominal Income Growth or Inflation?," American Economic Review, 92, 4, pp928-956.

[25] Kim, J., (2000), "Constructing and Estimating a Realistic Optimizing Model of Monetary Policy," Journal of Monetary Economics, 45, pp329-359.

[26] King, R., Plosser, C., Stock, J., and M. Watson, (1991), "Stochastic Trends and Economic Fluctuations," American Economic Review, 81, 4, pp819-840.

[27] McCallum, B., and E. Nelson, (1997), "An Optimizing IS-LM Specification for Monetary Policy and Business Cycle Analysis," National Bureau of Economic Research Working Paper \#5875.

[28] McCallum, B., and E. Nelson, (1999), "Nominal Income Targeting in and OpenEconomy Optimizing Model," Journal of Monetary Economics, 43, pp553-578.

[29] Nason, J., and G. Smith, (2003), "Identifying the New Keynesian Phillips Curve," University of British Columbia, mimeo (August, 2003).

[30] Rogoff, K., (1985), "The Optimal Degree of Commitment to an Intermediate Monetary Target," Quarterly Journal of Economics, 100, 4, pp1169-1189.

[31] Rotemberg, J., and M. Woodford, (1997), "An Optimization-Based Econometric Framework for the Evaluation of Monetary Policy," in Bernanke, B., and J. Rotemberg, (eds) NBER Macroeconomics Annual 1997, MIT Press, Cambridge.

[32] Rudd, J., and C. Whelan, (2003), "Can Rational Expectations Sticky-Price Models Explain Inflation Dynamics?," Board of Governors of the Federal Reserve System, mimeo (February, 2003).

[33] Rudebusch, G., (2001), "Is the Fed too Timid? Monetary Policy in an Uncertain World," Review of Economics and Statistics, 83, pp203-217. 
[34] Rudebusch, G., and L. Svensson, (1999), "Policy Rules for Inflation Targeting," in Taylor, J., (ed) Monetary Policy Rules, University of Chicago Press.

[35] Salemi, M., (2001), "Econometric Policy Evaluation and Inverse Control," University of North Carolina mimeo (December, 2001).

[36] Söderlind, P., (1999), "Solution and Estimation of RE Macromodels with Optimal Policy," European Economic Review, 43, pp813-823.

[37] Söderlind, P., Söderström, U., and A. Vredin, (2002), "Can Calibrated NewKeynesian Models of Monetary Policy Fit the Facts?" Sveriges Riksbank, mimeo (August, 2003).

[38] Schwarz, G., (1978), "Estimating the Dimension of a Model," Annals of Statistics, 6, pp461-464.

[39] Smets, F., and R. Wouters, (2002), "An Estimated Stochastic Dynamic General Equilibrium Model of the Euro Area," European Central Bank Working Paper \#171 (August, 2002).

[40] Taylor, J., (1993), "Discretion Versus Policy Rules in Practice," CarnegieRochester Conference Series on Public Policy, 39, pp195-214.

[41] Taylor, J., (1999), Monetary Policy Rules, University of Chicago Press, Chicago.

[42] Walsh, C., (2003), "Speed Limit Policies: The Output Gap and Optimal Monetary Policies," American Economic Review, 93, 1, pp265-278.

[43] Woodford, M., (2002), "Inflation Stabilization and Welfare," Contributions to Macroeconomics, vol. 2 , issue 1 , article 1 . 